\title{
NOTES
}

\section{Glycosyl Transfer Reaction to the Oligosaccharide Chain on the Synthetic Polymer}

\author{
Kenichi HatanaKa, ${ }^{\dagger}$ Yasushi Ito, Kozo Ishio, ${ }^{*}$ \\ and Toshiyuki URYU* \\ Department of Biomolecular Engineering, Tokyo Institute of Technology, \\ 4259 Nagatsuta-cho, Midori-ku, Yokohama 227, Japan \\ *Institute of Industrial Science, The University of Tokyo, \\ 7-22-1 Roppongi, Minato-ku, Tokyo 106, Japan
}

(Received April 15, 1994)

\begin{abstract}
KEY WORDS Oligosaccharide / Glycosyl Transferase / Glycosyl Acceptor / Blood Group / Polymeric Material / Acrylamide /
\end{abstract}

It has been reported that blood-group antigenic oligosaccharide chains play an important role in vivo. It is well-known that human blood-group antigen has $\mathrm{A}, \mathrm{B}$, or $\mathrm{H}$ type oligosaccharide chains in glycoproteins and glycolipids according to the blood group. ${ }^{1}$ The $\mathrm{N}$-acetylgalactosaminyl transferase (A enzyme) specifically transfers the sugar residue from UDP- $N$-acetylgalactosamine to the terminal galactose of the $\mathrm{H}$ substance to give A type oligosaccharide. Hakomori et al. isolated the gene which codes for the A enzyme. ${ }^{2}$ In the previous work, we synthesized a novel polymeric material having chemically synthesized $\mathrm{H}$ type oligosaccharide by copolymerization of oligosaccharide-containing monomer with acrylamide. $^{3}$ In this investigation, transfer of $\mathrm{N}$-acetyl-D-galactosamine to the galactose residue of $\mathrm{H} 1$ type oligosaccharide on the synthetic copolymer was attempted.

\section{EXPERIMENTAL}

\section{General Methods}

${ }^{1} \mathrm{H}$ NMR spectra were recorded on a JEOL
EX-270 spectrometer in deuterium oxide using sodium 4,4-dimethyl-4-silapentanesulfonate as internal standard. Gel permeation chromatography was carried out on $1 \%$ solution of the polymer in water by means of Shimadzu liquid chromatograph (Model LC-9A, column: Asahipak GS-510 (Asahi Chemical Industry Co.)). The number-average molecular weights of polymers were determined by GPC using standard pullulan as reference.

\section{Oligosaccharide-Containing Polymer}

Copolymerization of 5-(2-acryloyloxyethylcarbonyl)pentyl 2-acetamido-4,6-O-benzylidene-2-deoxy-3-O-[3,4,6-tri-O-benzyl-2-O$(2,3,4$-tri- $O$-benzyl- $\alpha$-L-fucopyranosyl)- $\beta$-Dgalactopyranosyl]- $\beta$-D-glucopyranoside and acrylamide was carried out in DMF with AIBN as catalyst at $70^{\circ} \mathrm{C}$ under high vacuum, and the obtained copolymer was deprotected as described previously. ${ }^{3}$ The structure of deprotected copolymer is shown in Figure 1. Mole fraction of 5-(2-acryloyloxyethylcarbonyl)pentyl 2-acetamido-4,6- $O$-benzylidene-2-deoxy-3$O$-[3,4,6-tri- $O$-benzyl-2- $O$-(2,3,4-tri- $O$-benzyl-

\footnotetext{
† To whom correspondence should be addressed.
} 


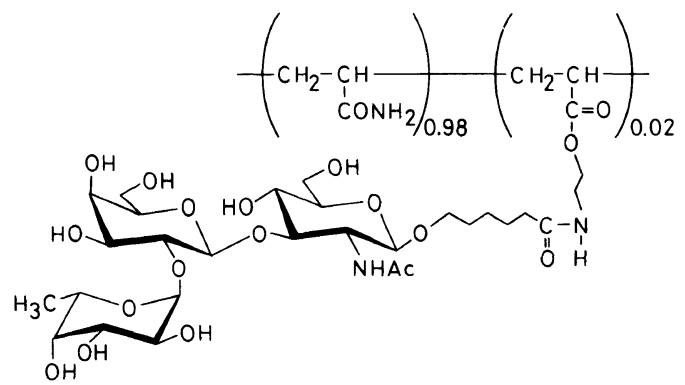

Figure 1. Copolymer of 5-(2-acryloyloxyethylcarbonyl)pentyl 2-acetamido-2-deoxy-3-O-[2-O-( $\alpha$-L-fucopyranosyl)- $\beta$-D-galactopyranosyl]- $\beta$-D-glucopyranoside and acrylamide.

$\alpha$-L-fucopyranosyl)- $\beta$-D-galactopyranosyl]- $\beta$ D-glucopyranoside in the copolymer, as measured by ${ }^{1} \mathrm{H}$ NMR spectroscopy, was 0.02 , and number-average molecular weight of the copolymer, as approximated by GPC, was $8.4 \times 10^{4}$.

Conversion of $H$ Type Oligosaccharide on the

Synthetic Polymer to A Type Oligosaccharide with GalNAc Transferase (A Enzyme)

UDP- $\left[{ }^{3} \mathrm{H}\right]-N$-Acetyl-D-galactosamine was purchased from New England Nuclear Corp., Boston, Mass. Human serum which contains an $\mathrm{N}$-acetyl-D-galactosaminyl transferase was prepared by centrifugation of the blood (type A) at $3000 \times g$ for $20 \mathrm{~min}$ at $4^{\circ} \mathrm{C}$ until use (within $5 \mathrm{~h}$ ).

The standard incubation mixtures contained $100 \mu \mathrm{l}$ of serum, $1 \mathrm{mg}$ of synthetic polymer having $\mathrm{H}$ type oligosaccharide, $0.02 \mathrm{nmol}$ $(0.33 \mu \mathrm{Ci})$ of UDP-[ $\left.{ }^{3} \mathrm{H}\right]-N$-acetyl-D-galactosamine, $5 \mu \mathrm{mol}$ of $\mathrm{MnCl}_{2}$, and $100 \mu \mathrm{l}$ of $0.3 \%$ Triton X-100 in $0.1 \mathrm{M}$ Tris or HEPES buffer $\mathrm{pH} \mathrm{7.2,} \mathrm{all} \mathrm{in} \mathrm{a} \mathrm{total} \mathrm{volume} \mathrm{of} 0.22 \mathrm{ml}$. The incubation was carried out $37^{\circ} \mathrm{C}$ for $10 \mathrm{~h}$ and the reaction was terminated by cooling on an ice bath. $100 \mu \mathrm{l}$ of the reaction mixture was applied to a gel filtration (Sephadex G-50, Pharmacia). The column was eluted with $0.02 \mathrm{M}$ ammonium acetate buffer $(\mathrm{pH} 7.0)$ and fractionated. Each fraction $(100 \mu \mathrm{l})$ was mixed with $3 \mathrm{ml}$ of Liquiscint and examined for

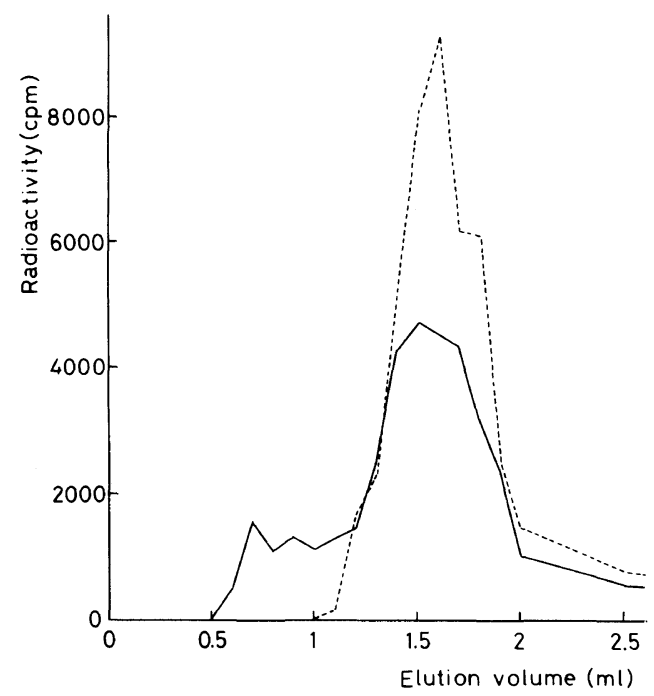

Figure 2. Incorporation of $\left[{ }^{3} \mathrm{H}\right]-N$-acetyl-D-galactosamine into the copolymer having $\mathrm{H}$-type antigenic oligosaccharide catalyzed by A enzyme in human plasma. Solid line; incubated with the synthetic copolymer; dashed line; incubated without the synthetic copolymer.

radioactivity in a liquid scintillation spectrometer.

\section{RESULTS AND DISCUSSION}

Glycosyl transferases catalyze the trasfer of glycosyl residue from the sugar nucleotides (glycosyl donor) to the acceptors. Each enzyme has a strict acceptor specificity and gives a characteristic glycosidic linkage. In this research, we investigated whether the synthetic $H$ type oligosaccharide in the copolymer is recognized by glycosyl transferase which catalyzes biosynthesis of the A type antigenic oligosaccharide within the body of blood type A.

The synthesized polymer having an $\mathrm{H}$ type oligosaccharide was incubated with UDP$\left[{ }^{3} \mathrm{H}\right]-N$-acetyl-D-galactosamine and human serum (blood type A). The incubation mixture was applied to the gel filtration in order to separate the polymer from unreacted UDP$\left[{ }^{3} \mathrm{H}\right]-N$-acetyl-D-galactosamine. The obtained fractions were examined for radioactivity in a 
liquid scintillation spectrometer. The result is shown in Figure 2. Some radioactivity was observed in the high-molecular-weight fractions, indicating that some radioactive $N$ acetyl-D-galactosamine was transfered to the polymer having an $\mathrm{H}$ type oligosaccharide.

The transfer of $\mathrm{N}$-acetyl-D-galactosamine was observed. However, the degree of transfer was quite low, indicating that the artificial oligosaccharide-containing polymer is not a good acceptor. The radioactivity observed in fractions eluted from $0.5 \mathrm{ml}$ to $1 \mathrm{ml}$ was only $17 \%$ of the whole activity. This tendency hardly changed even if the serum (A enzyme) from the different donor or the different kind of incubation buffer was used. Systematic investi- gation of the interaction between the synthetic polymers having different degrees of oligosaccharide substitution or different kinds of main chains and biomolecules such as glycosyl transferase may develop new bioactive polymer materials.

\section{REFERENCES}

1. W. M. Watkins and W. T. Morgan, Vox. Sang, 4, 97 (1959).

2. H. Clausen, T. White, K. Takio, M. Stroud, E. Holmes, J. Karkov, L. Thim, and S. Hakomori, $J$. Biol. Chem., 265, 1139 (1990).

3. K. Hatanaka, Y. Ito, A. Maruyama, Y. Watanabe, T. Akaike, K. Ishio, and T. Uryu, Macromolecules, 26, 1483 (1993). 